\title{
EEG study of the cortical representation and classification of the emotional connotations in words
}

Yuqiao Gu ${ }^{1 *}$, Massimo Poesio ${ }^{1,2}$, Brian Murphy ${ }^{3}$

From The Twenty Third Annual Computational Neuroscience Meeting: CNS*2014

Québec City, Canada. 26-31 July 2014

There has recently been a surge of interest in searching the neural basis of emotional connotations in words, using fMRI, MEG and EEG [1-4]. In this work we use a linguistically controlled set of 36 English word stimuli, where emo- tional valence and concreteness are cross-classified, and present them visually to five English native speakers (aged 26-39yrs, mean 34). EEG signals were recorded from the participants while they performed a mental simulation

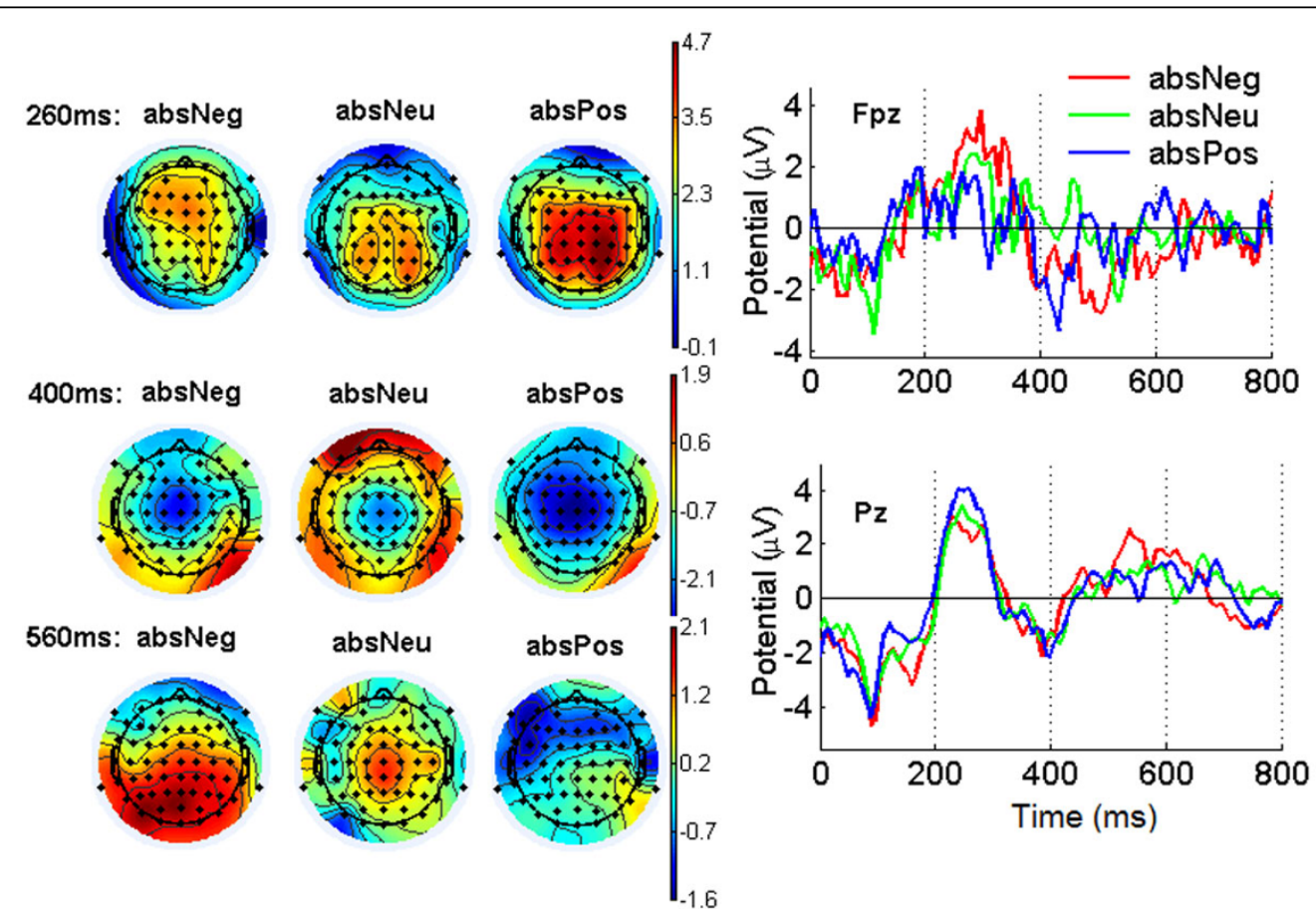

Figure 1 Grand mean ERPs elicited by abstract word stimuli. Left panel: ERP scalp maps at three time points of P300, N400 and P600 respectively; right panel: ERP waveform; at a prefrontal and a parietal EEG channel.

\footnotetext{
* Correspondence: yuqiao.gu@unitn.it

${ }^{1}$ CLIC, CIMeC - Center for Mind/Brain Sciences, Università degli Studi di

Trento, Rovereto (TN), I - 38068, Italy

Full list of author information is available at the end of the article
}

(c) $2014 \mathrm{Gu}$ et al; licensee BioMed Central Ltd. This is an Open Access article distributed under the terms of the Creative Commons 
task. We use event-related potential (ERP) and multivariate pattern analyses (MVPA) to investigate the cortical representation and classification of emotional valence, for concrete words and abstract words separately. The grand mean ERPs elicited by abstract words over the five subjects show four typical ERP components: N100, P300, N400 and P600 (Fig. 1). For the P300 waveform, in prefrontal areas the amplitude of negative words is the largest, while that of positive words is the smallest; in contrast, in centralparietal-occipital regions the amplitude of positive words is the largest, whereas that of the negative words is the smallest. For the N400, the negative deflection of positive words is the largest, while that of the neutral words is the smallest in frontal-central areas. For P600, the amplitude of negative words is the largest in the posterior regions. For concrete words, the ERP patterns are broader, but with some important differences with regard to abstract words. The amplitude of P300 of negative words are closer to that of neutral words in the prefrontal area. There are no clear differences between negative, neutral and positive words during the P600. We then Use EEG amplitudes features extracted in the time-domain to train a sparse multinomial logistic regression (SMLR) classifier for three-way valence classification. The mean classification accuracy over the 5 subjects is $39.5 \%$ for abstract words and $41.0 \%$ for concrete words, which are above the chance level of $33.3 \%$.

\section{Authors' details}

${ }^{1}$ CLIC, CIMeC - Center for Mind/Brain Sciences, Università degli Studi di Trento, Rovereto (TN), I - 38068, Italy. ${ }^{2}$ School of Computer Science and Electronic Engineering, University of Essex, Colchester, CO7 9QZ, UK.

${ }^{3}$ Knowledge \& Data Engineering (EEECS) Queen's University Belfast, UK.

Published: 21 July 2014

\section{References}

1. Crosson B, Radonovich K, Sadek JR, Gökcay D, Bauer RM, Fischler IS, Cato MA, Maron L, Auerbach EJ, Browd SR, Briggs RW: Left-hemisphere processing of emotional connotation during word generation. NeuroReport 1999, 10(12):2449-2455.

2. Hamann S, Mao H: Positive and negative emotional verbal stimuli elicit activity in the left amygdala. NeuroReport 2002, 13(1):15-19.

3. Hirata M, Koreeda S, Sakihara K, Kato A, Yoshimine T, Yorifuji S: Effects of the emotional connotations in words on the frontal areas-a spatially filtered MEG study. Neuroimage 2007, 35(1):420-429.

4. Inaba M, Kamishima $\mathrm{K}$, Ohira $\mathrm{H}$ : An electrophysiological comparison of recollection for emotional words using an exclusion recognition paradigm. Brain Research 2007, 1133:100-109.

\section{doi:10.1186/1471-2202-15-S1-P81}

Cite this article as: Gu et al:: EEG study of the cortical representation and classification of the emotional connotations in words. BMC Neuroscience 2014 15(Suppl 1):P81.

\section{Submit your next manuscript to BioMed Central} and take full advantage of:

- Convenient online submission

- Thorough peer review

- No space constraints or color figure charges

- Immediate publication on acceptance

- Inclusion in PubMed, CAS, Scopus and Google Scholar

- Research which is freely available for redistribution

Submit your manuscript at www.biomedcentral.com/submit
C Biomed Central 